\title{
Dynamic expression of proteins associated with adventitial remodeling in adventitial fibroblasts from spontaneously hypertensive rats
}

\author{
Shu-jie GUO ${ }^{1,2,3}$, Tai-rong WANG ${ }^{4}$, Jing $\mathrm{CHEN}^{1,2,3}$, Ling-yun WU ${ }^{1,2}$, Ping-jin GAO ${ }^{1,2,3, *}$, Ding-liang ZHU ${ }^{1,2,3, *}$
}

${ }^{1}$ State Key Laboratory of Medical Genomics, Shanghai Key Laboratory of Vascular Biology and Department of Hypertension, Ruijin Hospital, Shanghai JiaoTong University School of Medicine, Shanghai 200025, China; ${ }^{2}$ Laboratory of Vascular Biology, Institute of Health Sciences, Shanghai Institute for Biological Sciences, Chinese Academy of Sciences, Shanghai 200025, China; ${ }^{3}$ Shanghai Institute of Hypertension, Shanghai 200025, China; ${ }^{4}$ Luwan Branch, Ruijin Hospital, Shanghai Jiaotong University School of Medicine, Shanghai 200025, China

Aim: To identify proteins that could potentially be involved in adventitial remodeling in vascular adventitial fibroblasts (AFs) from spontaneously hypertensive rats (SHR).

Methods: AFs were isolated from thoracic aortas of 4-, 8-, 16-, and 24-week-old male SHR and Wistar-Kyoto (WKY) rats and cultured to passage 4. Proteomic differential expression profiles between SHR-AFs and WKY-AFs were investigated using 2-D electrophoresis (2-DE), whereas gel image analysis was processed using Image Master 2D Platinum. Protein spots were identified using matrix-assisted laser desorption/ionization time-of-flight mass spectrometry (MALDI-TOF-MS). Expression levels of annexin A1 in AFs and aortas from SHR and WKY rats were detected with Western blotting and immunofluorescence techniques.

Results: In 4-, 8-, 16-, and 24-week-old SHR-AFs, 49, 59, 54, and 69 protein spots were found to have significant differences from the age-matched WKY-AFs. Fourteen spots with the same changes in patterns were analyzed in 4-, 8-, 16-, and 24-week-old SHR-AFs with mass spectrometry. Except for cytoskeleton proteins such as tubulin beta 5, it was found that annexin A1, translation elongation factor Tu, endoplasmic reticulum protein 29 and calcium-binding protein 1 were expressed in vascular AFs and their levels changed significantly in SHR-AFs compared with those in WKY-AFs. A decrease in annexin A1 in SHR-AFs was confirmed with Western blotting and immunofluorescence staining at the cell and tissue levels.

Conclusion: The application of proteomic techniques revealed a number of novel proteins involved in adventitial remodeling of AFs from SHR, which provide new mechanisms responsible for the occurrence and development of hypertension and potential targets for influencing vascular remodeling in hypertension.

Keywords: adventitia; adventitial fibroblasts; vascular remodeling; spontaneously hypertensive rats; two-dimensional electrophoresis; MALDI-TOF-MS; annexin

Acta Pharmacologica Sinica (2010) 31: 1312-1318; doi: 10.1038/aps.2010.88; published online 30 Aug 2010

\section{Introduction}

Vascular remodeling has traditionally been thought to occur through abnormalities in vascular endothelial and media cells. In recent years, however, evidence has emerged suggesting that the vascular adventitia is the "first responder" and that adventitial remodeling is the initiator of vascular remodeling in a variety of cardiovascular diseases ${ }^{[1-3]}$. Adventitial fibroblasts (AFs) differentiate into myofibroblasts (MFs) that are

\footnotetext{
* To whom correspondence should be addressed.

E-mail zhudingliang@sibs.ac.cn (Ding-liang ZHU); gaopingjin@yahoo.com.cn (Ping-jin GAO)

Received 2010-04-12 Accepted 2010-06-09
}

capable of proliferating, migrating and synthesizing extracellular matrices. Phenotypic differentiation of AFs into MFs has long been thought to be a key step in vascular remodeling ${ }^{[4,5]}$. Results from our laboratory have shed light on the role and mechanism of transformation of AFs into MFs in vascular remodeling over the last decades. However, the role of AFs in adventitial remodeling following chronic vascular injury, such as in hypertensive individuals, is rarely presented. $\mathrm{Zhu}^{[6]}$ first found that spontaneously hypertensive rats (SHR)-AFs proliferated faster than Wistar Kyoto rats (WKY)-AFs, and increased cell density in the adventitia of stroke-prone SHR was revealed by confocal microscopy ${ }^{[7]}$. Moreover, we also found that the migration of SHR-AFs was always greater than 
that of WKY-AFs after treatment with various stimulators ${ }^{[8,9]}$. Nevertheless, the mechanism of adventitial remodeling in SHR remains elusive. Higher-throughput techniques of proteomics and genomics are necessary to study the alterations of genes and proteins in SHR-AFs in order to obtain a better understanding of the increased proliferation and migration of SHR-AFs. In this study, the proteomic differential expression profiles of SHR-AFs compared with age-matched WKY-AFs from animals 4 weeks to 24 weeks of age were investigated to explore proteins that are potentially related to adventitial remodeling in SHR-AFs during the occurrence and development of hypertension.

\section{Materials and methods Cell culture}

The rats used in this study were 4-, 6-, 8-, and 24-week-old male SHR and WKY rats with specific pathogen-free (SPF) grades, purchased from the Shanghai Institute of Hypertension. All experimental procedures were performed according to the guidelines of the Animal Care Committee of the Animal Center at the Chinese Academy of Sciences in Shanghai, China. One adventitial fibroblasts sample was isolated from two rat thoracic aortas ${ }^{[6]}$, and each group consisted of three samples. Cells were grown in DMEM supplemented with $10 \%$ heat-inactivated FCS, $1 \%$ L-glutamine, $100 \mathrm{U} / \mathrm{mL}$ penicillin, and $100 \mu \mathrm{g} / \mathrm{mL}$ streptomycin. Cells were used in passage 4. The subconfluent cells were made quiescent by being incubated in DMEM supplemented with $0.1 \%$ BSA for $48 \mathrm{~h}$ before harvest.

\section{Sample preparation}

Cells were counted and harvested by centrifugation, washed twice with Tris-buffered sucrose $(10 \mathrm{mmol} / \mathrm{L}$ Tris base, $250 \mathrm{mmol} / \mathrm{L}$ sucrose, $\mathrm{pH}$ 7.0), and dissolved in lysis buffer containing $7 \mathrm{~mol} / \mathrm{L}$ urea, $2 \mathrm{~mol} / \mathrm{L}$ thiourea, 4\% CHAPS, 40 $\mathrm{mmol} / \mathrm{L}$ DTT, $40 \mathrm{mmol} / \mathrm{L}$ Tris base, and 2\% IPG buffer $\mathrm{pH}$ 3-10. After vortex incubation at room temperature for $1 \mathrm{~h}$, samples were centrifuged at $40000 \times g$ and $4{ }^{\circ} \mathrm{C}$ for $1 \mathrm{~h}$. The supernatant was quantified using the Bradford assay and aliquoted. The protein samples were stored at $-80{ }^{\circ} \mathrm{C}$ until analysis.

\section{Two-dimensional electrophoresis and analysis}

Soluble proteins were separated by 2-DE. Protein $(200 \mu \mathrm{g}$ for silver staining and $2 \mathrm{mg}$ for Coomassie Brilliant Blue G-250 staining) was diluted in rehydration buffer containing $8 \mathrm{~mol} / \mathrm{L}$ urea, 2\% CHAPS, $20 \mathrm{mmol} / \mathrm{L}$ DTT, 0.5\% IPG buffer $\mathrm{pH} 3-10$ and $0.002 \%$ bromophenol blue and was applied to 24-cm IPG strips with a nonlinear $\mathrm{pH}$ range of 3-10 (GE Healthcare, Uppsala, Sweden). The first dimension was performed with the IPGphor system (GE Healthcare) according to the programmed settings: $30 \mathrm{~V}$ for $6 \mathrm{~h}, 60 \mathrm{~V}$ for $6 \mathrm{~h}, 200 \mathrm{~V}$ for $1 \mathrm{~h}, 500 \mathrm{~V}$ for $1 \mathrm{~h}, 1000 \mathrm{~V}$ for $1 \mathrm{~h}, 8000 \mathrm{~V}$ for $1 \mathrm{~h}$ at gradient type and $8000 \mathrm{~V}$ until reaching $55 \mathrm{kV} \cdot \mathrm{h}$. Then, the IPG strips were equilibrated for $15 \mathrm{~min}$ in a buffer containing $6 \mathrm{~mol} / \mathrm{L}$ urea, $30 \%$ glycerol, $2 \%$ SDS and $0.02 \%$ bromophenol blue with
$10 \mathrm{mg} / \mathrm{mL}$ DTT and then equilibrated for another $15 \mathrm{~min}$ in the same buffer but with $25 \mathrm{mg} / \mathrm{mL}$ iodoacetamide replacing DTT. The second-dimensional separations were performed on $12.5 \%$ SDS-polyacrylamide gels with the Ettan Dalt twelve (GE Healthcare) initially set at $5 \mathrm{~W}$ per gel for $30 \mathrm{~min}$ and then at $20 \mathrm{~W}$ per gel until the dye front reached the gel bottom. Silver staining and Coomassie Brilliant Blue G-250 staining were performed as previously described ${ }^{[10,11]}$. The stained gels were scanned using ImageScanner II (GE Healthcare) and analyzed with ImageMaster 2D Platinum (GE Healthcare). The intensities of the spots were normalized based on the total volumes on the gel. Protein spots with significant changes (paired $t$-test, $P<0.05$ ) in a consistent direction (increase or decrease in three independent experiments and in cells from rats at four weeks of age) or with altered locations were excised for identification.

\section{Matrix-assisted laser desorption/ionization time-of-flight mass spectrometry (MALDI-TOF-MS) and database search}

The protein spots were excised from 2-D gels stained with Coomassie Blue G-250 and digested as previously described ${ }^{[12]}$. Aliquots $(0.5 \mu \mathrm{L})$ of the tryptic peptides were mixed with 1.5 $\mu \mathrm{L}$ of a matrix solution consisting of a saturated solution of alpha-cyano-4-hydroxycinnamic acid in 50\% acetonitrile/ $0.1 \%$ TFA. The mixture $(1 \mu \mathrm{L})$ was immediately placed onto a MALDI plate and dried at room temperature. The dried spots were analyzed in a Bruker-Daltonics AutoFlex TOF-TOF LIFT Mass Spectrometer (Bruker-Franzen, Germany) in reflex positive ion mode at an accelerating voltage of $20 \mathrm{kV}$ and a reflex voltage of $23 \mathrm{kV}$. The spectra were internally calibrated using trypsin autolysis products. The peptide mass fingerprints (PMF) obtained were used to search through the SWISSPROT and NCBInr databases using the Mascot search engine (http://www.matrixscience.co.uk) with a tolerance of $0.2 \mathrm{D}$ and one missed cleavage site ${ }^{[12]}$.

\section{Western blot}

The protein lysates (30 $\mathrm{\mu g}$ protein per lane) were analyzed as previously described ${ }^{[13]}$. Annexin A1 was detected by antiannexin A1 antibody (Santa Cruz, USA). $\beta$-actin was detected by mouse anti- $\beta$-actin mAb (Sigma-Aldrich, USA) to confirm equal loading.

\section{Immunofluorescence staining}

The expression of annexin A1 in the thoracic aortas of 16-week-old SHR and WKY rats was analyzed by immunofluorescence staining. Cryosections of the aortae ( $8-\mu \mathrm{m}$ thick) were thawed and fixed in ice-cold acetone for $10 \mathrm{~min}$. Nonspecific binding was blocked in 5\% BSA for $1 \mathrm{~h}$. Tissue sections were incubated with Annexin A1 antibodies (1:200, Santa Cruz Biotechnology). After being rinsed with PBS, tissue sections were incubated with secondary antibody conjugated to FITC (1:100). Then, sections were stained with DAPI (1:10000) at room temperature for $10 \mathrm{~min}$ after washing with PBS. Fluorescent images were acquired using a Nikon Eclipse 80i microscope and analyzed using MetaMorph image-analysis 
software $(n=3)$.

\section{Statistical analysis}

The values were expressed as means \pm SD. The paired $t$-test was used for statistical analysis between two groups. The significant level was set at $P<0.05$.

\section{Results}

Comparison of protein expression profiles between SHR-AFs and WKY-AFs

To explore the differences in protein expression between SHRAFs and WKY-AFs, the proteins from SHR-AFs and WKYAFs from 4-, 8-, 16-, and 24-week-old mice were separated by 2-DE. Gels using three different samples from the same group were performed simultaneously and analyzed by ImageMaster 2D Platinum Analysis Software. In total, 1228 \pm 132 spots were detected on the maps, and the overall protein expression profiles with $\mathrm{pH} 3-10$ and molecular masses of 10 to $90 \mathrm{kDa}$ were very similar within the three samples of the same group as analyzed by ImageMaster 2D Platinum, indicating high stability and reproducibility of the 2-DE in our test system. In comparison with the 2-DE maps of age-matched WKYAFs, the number of altered spots, up-regulated spots, downregulated spots and spots with changed locations for SHR-AFs were, respectively, as follows: 4-week-old rats, 49, 29, 19, and 1 spots; 8-week-old rats, 59, 34, 23, and 2 spots; 16-week-old rats, 54, 33, 20, and 1; and 24-week-old rats, 69, 42, 25, and 2. Thirteen protein spots with significant changes in volume (paired $t$-test, $P<0.05$ ) in a consistent direction (increased or decreased in all three samples per group and in four age groups) and one spot with an altered location were judged as differential spots and excised for identification as noted in Figures 1 and 2.

Identification by MALDI-TOF-MS with peptide mass fingerprinting (PMF)

These 14 excised spots were identified by MALDI-TOF-MS analysis with PMF followed by database searching. The prop- erties and changes of identified proteins with altered expression in SHR-AFs compared to that in age-matched WKY-AFs are presented in Table 1 and Figure 2. Among them, there were eight proteins with definite biological functions, two proteins with undefined function and four proteins derived from a genomic sequence. Eight proteins were separately involved in inflammation, energy metabolism, molecular chaperon, cell cycle and proliferation, cytoskeleton, and regulation of ion influx.

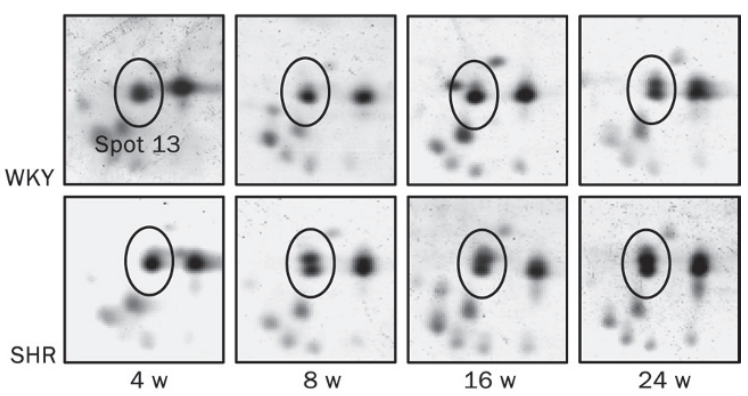

Figure 2. Altered location of spot 13 in 2-DE maps of vascular adventitia fibroblasts from SHR and WKY rats.

\section{Annexin A1 decreased in SHR-AFs}

Annexin A1 (spot 4 in Table 1), a putative inflammationrelated protein, presented consistent changes between SHRAFs and WKY-AFs from 4-, 8-, 16-, and 24-week-old rats (Table 1), which was confirmed by Western blot analysis. Annexin A1 was down-regulated in SHR-AFs from 4-, 8-, and 16 -week-old rats compared with expression in age-associated WKY-AFs (paired $t$-test, $P<0.05$ ), and Annexin A1 expression tended to be lower in SHR-AFs from 24-week-old rats compared with that in age-matched WKY-AFs, although significance was not achieved as observed in Figure 3. Moreover, the effect of age on Annexin A1 expression was different between the two strains. Annexin A1 expression was reduced with
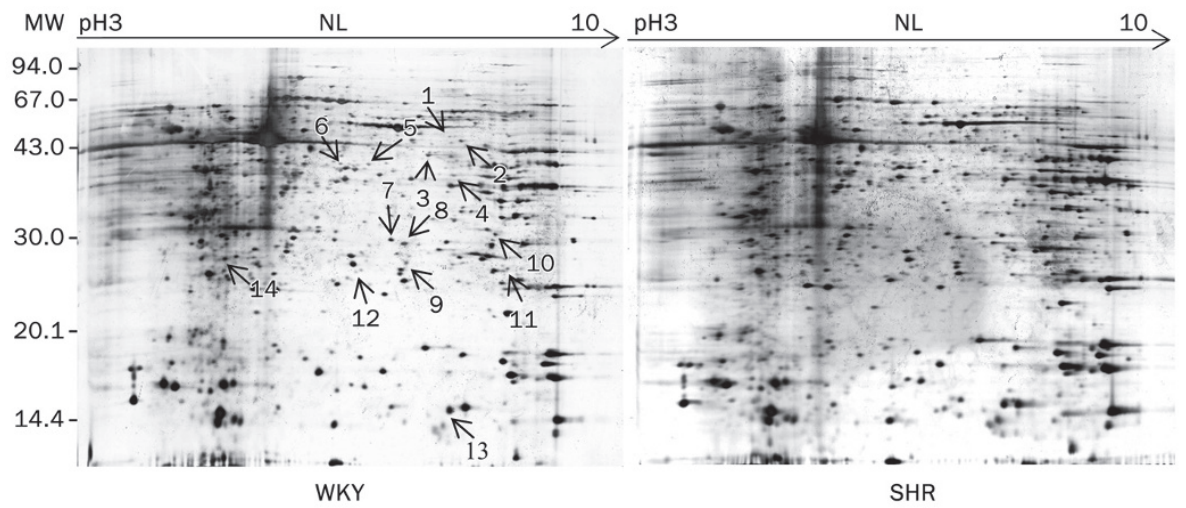

Figure 1. Representative 2-DE maps of vascular adventitia fibroblasts from SHR and WKY rats and differentially expressed protein spots that were further identified by mass spectral analysis. Cell lysates $(200 \mu \mathrm{g})$ were loaded onto IPG strips (24-cm, pH 3-10 non-linear), followed by the second dimension on a vertical continuous gel (12.5\%), and visualized by silver staining. The horizontal dimension of the images represents the linear immobilized $\mathrm{pH}$ gradient for IEF. The positions of standard mass biomarkers for the second dimension are shown on the left sides of images. The identified proteins were labeled with arrows and the Arabic numeral represents the number of spots. $n=3$. 


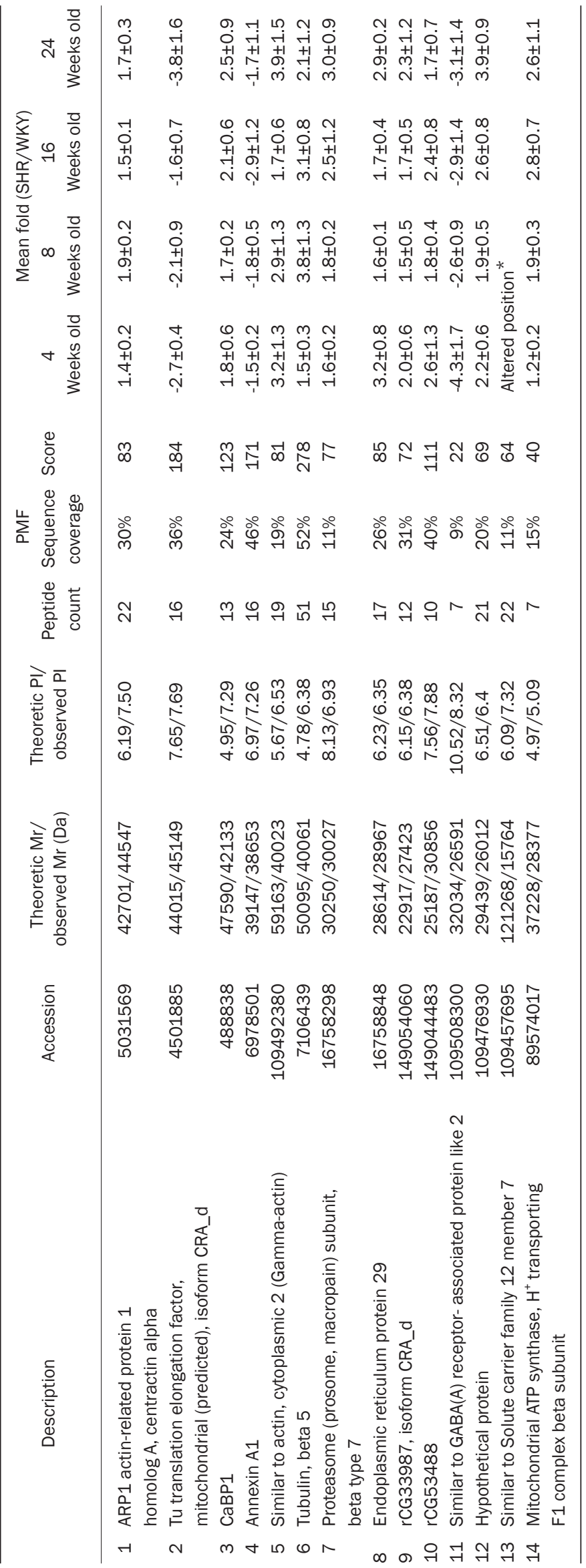

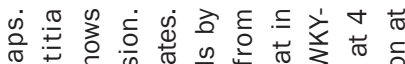
है 山 ่ิ

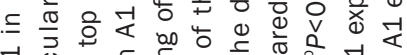

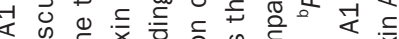

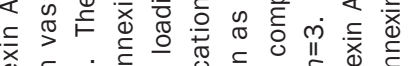

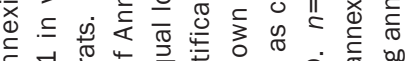

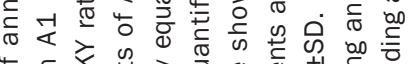

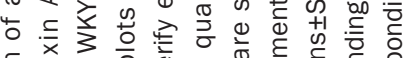

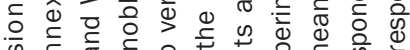

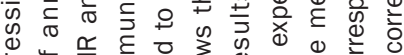

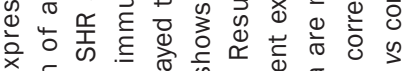

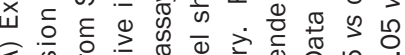

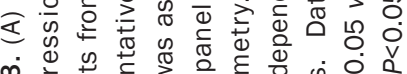

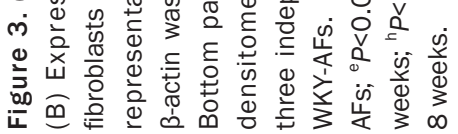

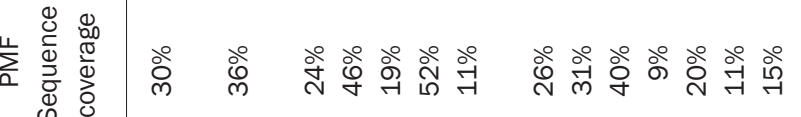

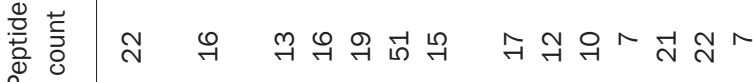

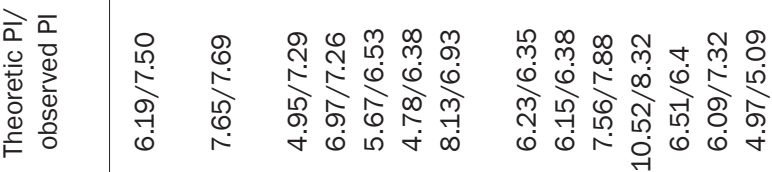

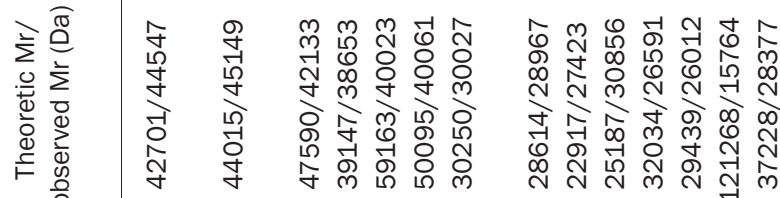

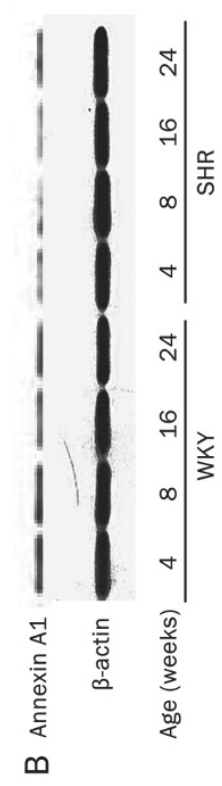

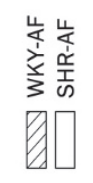
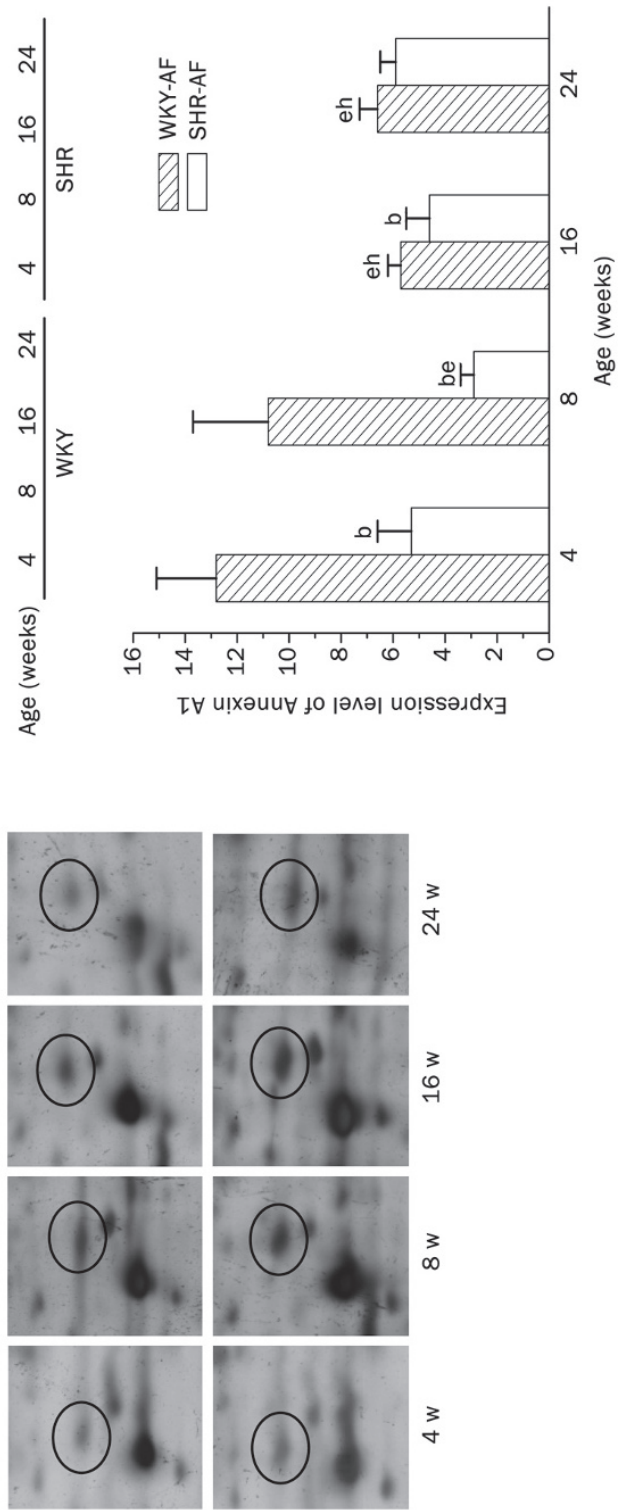
age in WKY-AFs, while in SHR-AFs, no obvious association of annexin A1 expression with age was exhibited.

To make further confirmation, we detected Annexin A1 expression in thoracic aortic sections from 16-week-old SHR and WKY rats. Immunofluorescence indicated that the total annexin A1 immunofluorescence intensity was $8.72 \pm 2.97$ units in tissue sections of SHR rats compared with $46.89 \pm 8.75$ units in tissue sections of WKY rats. In tissue sections, the annexin A1 signal was mainly detected in the adventitia (Figure 4).

\section{Discussion}

In this study, we identified 13 proteins with consistently altered expression in pre-hypertensive and hypertensive stage SHR-AFs with MALDI-TOF-MS. The higher relative weights and protein contents found in aortas from newborn SHR may reflect a remodeling of this organ ${ }^{[14]}$. In addition, an adventitial remodeling in SHR was demonstrated by the increased proliferation and migration in AFs from SHR at the cytological level. The appearance of aorta hypertrophy so early in the hypertensive process indicates an intrinsic abnormality in the aorta of SHR not caused by the pressure overload that we used as a basis to select proteins with changes in 4-, 8-, 16-, and 24-week-old SHR-AFs. Moreover, we also chose a spot for identification that divided into two spots in 8-week-old and 16-week-old SHR-AFs because this change suggests that the identified spot was a proteolytic degradation product or the result of other post-translational modifications.

Of special interest, the expression of annexin A1 (spot 4), a putative anti-inflammation factor, was significantly downregulated in SHR-AFs as compared with expression in agematched WKY-AFs at all ages in the present study. Annexin A1 is a member of the family of phospholipid and calciumbinding proteins and has been implicated in several cell functions, including inhibition of cell proliferation, anti-inflammatory effects, regulation of cell differentiation, and membrane trafficking. For cell proliferation, annexin A1 has been shown to inhibit OKT3-stimulated and mitogen-induced cellular pro- liferation of $\mathrm{T}$ cells ${ }^{[15]}$ and to be involved in mitogenic signal transduction by $\mathrm{HGF}^{[16]}$, glucocorticoids ${ }^{[17]}$, and the growth hormone receptor ${ }^{[18]}$. Furthermore, the active N-terminal peptide of annexin A1 has been reported to block EGF-induced cell proliferation ${ }^{[19]}$. In this paper, decreased expression of annexin A1 perhaps attenuates the negative regulation of cell proliferation and results in increased proliferation in SHRAFs. Based on this finding, we sought to determine the mechanism by which annexin A1 modulates SHR-AF function. The antiproliferative mechanism of annexin A1 appears to involve modulation of the ERK signaling pathway. Annexin A1 has been shown to modulate ERK but not p38 or JNK activity in lipopolysaccharride-induced responses ${ }^{[20]}$ and regulate cell proliferation by disruption of cell morphology and inhibition of cyclin D1 expression through sustained activation of the ERK1/2 MAPK pathway ${ }^{[21]}$. Our previous studies showed that ERK1/2 was activated during phenotypic differentiation of AFs into $\mathrm{MFs}^{[22]}$ and migration induced by Ang $\mathrm{II}^{[23]}$. Moreover, annexin $\mathrm{A} 1$ is a substrate for protein kinase $\mathrm{C}$ (PKC) and protein tyrosine kinases and has multiple phosphorylation sites as well as calcium and phospholipid binding properties. Whether PKC alpha, another molecule involved in phenotypic differentiation of AFs into $\mathrm{MFs}^{[24]}$, attenuates annexin A1 activity and regulates SHR-AF proliferation through the ERK1/2 MAPK pathway is another area of interest.

Two other proteins involved in mitochondrial function, translation elongation factor $\mathrm{Tu}(\mathrm{EF}-\mathrm{Tu})$ and mitochondrial ATP synthase, $\mathrm{H}^{+}$transporting $\mathrm{F} 1$ complex, beta subunit (ATP5B), were identified. Expression of EF-Tu (spot 2) was decreased and that of ATP5B (spot 14) was increased in SHRAFs as compared with the age-matched WKY-AFs. The coupling step in the biosynthesis of ATP in mitochondria is generally believed to involve an energy-requiring release of ATP that is bound to ATP5B. Higher consumption of energy due to increased proliferation and migration of SHR-AFs may require more ATP5B involvement in this process. In mitochondria, the major target of phosphorylation was EF-Tu ${ }^{[25,26]}$.
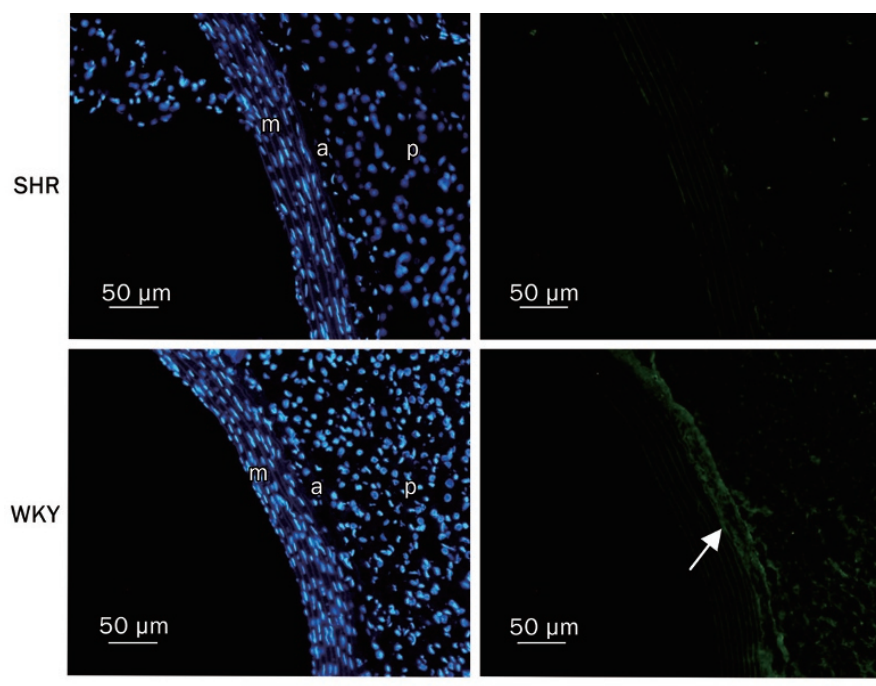

DAPI

Annexin A1
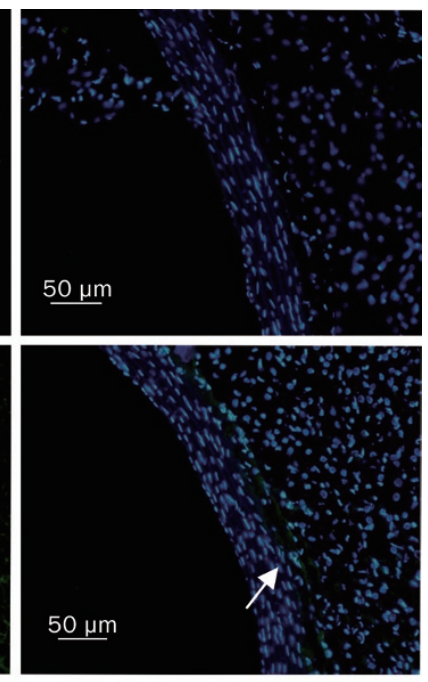

Merge
Figure 4. Expression of annexin A1 in thoracic aortae from 16-weekold SHR and WKY rats. Aortic tissue from 16-week-old SHR and WKY rats subjected to immunofluorescence staining to detect annexin A1 antigen. Annexin A1 was decreased in aortic adventitia from 16-week-old SHR rats. Scale bar: $50 \mu \mathrm{m}$; $\mathrm{m}$ indicates media, a indicates adventitia, $P$ indicates perivascular adipose tissue. Total magnification: $\times 100$. 
The phosphorylation of EF-Tu is increased in response to ischemia and in mitochondria from ischemic hearts ${ }^{[25]}$. Otherwise, EF-Tu content nearly disappears in pacing-induced heart failure, along with a number of other mitochondrial proteins ${ }^{[27]}$. The status of EF-Tu in hypertension or abnormal vasculature remains elusive. Further work will be necessary to understand the function of EF-Tu in AFs and the relationship between the content and phosphorylation of EF-Tu.

The expression of endoplasmic reticulum protein 29 (ERp29) (spot 8), a critical chaperone for protein maturation and secretion $^{[28-30]}$, increased in SHR-AFs, which may indicate that secretory behavior in SHR vasculature is more active than in WKY vasculature. The culture components of supernatants derived from SHR-AFs and WKY-AFs is being investigated.

A protein involved in cell cycle and proliferation, proteasome subunit beta type 7 (spot 7), was identified as having increased expression in SHR-AFs. This result is similar to that of our previous study, which showed that proteasome subunit beta type 4 was increased in myofibroblasts with characteristic of higher proliferation and migration rate induced by Ang II and TGF- $\beta 1^{[31]}$.

CaBP1 (spot 3), another protein with increased expression in SHR-AFs, has been shown to regulate TRPC5, voltagegated $\mathrm{Ca}^{2+}$ channels and inositol 1,4,5-trisphosphate receptors (IP3Rs) in neurons and Xenopus oocytes. The role of CaBP1 in the cardiovascular system remains unknown. The expression of other proteins such as ARP1 actin-related protein 1 homolog A (spot 1) and tubulin beta 5 (spot 6) was up-regulated in SHR-AFs. Their roles in vascular remodeling in hypertension are still unknown. Among the four proteins derived from a genomic sequence, the altered location of spot 13 suggested that the identified spot was a proteolytic degradation product or the result of other post-translational modifications and worthy of deep mass spectral analysis.

In conclusion, the application of proteomic techniques revealed novel proteins involved in abnormalities of AFs from SHR, which provide new avenues for investigating the mechanisms responsible for the occurrence and development of hypertension and potential targets for altering vascular remodeling in hypertension.

\section{Acknowledgements}

This work was supported by grants from the National Key Project of Basic Research (2006CB503804, 2009CB521905)and the National Natural Science foundation of China (30670832, 30870941, 30871085); the Shanghai Education Committee (09YZ101) and the Shanghai Science and Technology Committee (08JC1417400, 08ZR1422000, 08PJ1408000, 08DZ2200400, 08410702400, 09540704600). Support for mass spectrometry analysis by the Research Center for Proteome Analysis of the Institute of Biochemistry and Cell Biology in the Shanghai Institutes for Biological Sciences at the Chinese Academy of Sciences is also gratefully acknowledged.

\section{Author contribution}

Shu-jie GUO, Ping-jin GAO, Ding-liang ZHU designed the study; Shu-jie GUO, Tai-rong WANG, Jing CHEN, Ling-yun WU performed the research; Shu-jie GUO, Ping-jin GAO, Ding-liang ZHU contributed new reagents and analytic tools; Shu-jie GUO analyzed the data; Shu-jie GUO wrote the paper.

\section{References}

1 Scott NA, Cipolla GD, Ross CE, Dunn B, Martin FH, Simonet L, et al. Identification of a potential role for the adventitia in vascular lesion formation after balloon overstretch injury of porcine coronary arteries. Circulation 1996; 93: 2178-87.

2 Arribas SM, González C, Graham D, Dominiczak AF, McGrath JC. Cellular changes induced by chronic nitric oxide inhibition in intact rat basilar arteries revealed by confocal microscopy. J Hypertens 1997; 15: 1685-93.

3 Kantachuvesiri S, Fleming S, Peters J, Peters B, Brooker G, Lammie $A G$, et al. Controlled hypertension, a transgenic toggle switch reveals differential mechanisms underlying vascular disease. J Biol Chem 2001; 276: 36727-33.

4 Shi Y, Pieniek M, Fard A, O’Brien J, Mannion JD, Zalewski A. Adventitial remodeling after coronary arterial injury. Circulation 1996; 93: 340-8.

5 Li G, Chen SJ, Oparil S, Chen YF, Thompson JA. Direct in vivo evidence demonstrating neointimal migration of adventitial fibroblasts after balloon injury of rat carotid arteries. Circulation 2000; 101: 1362-5.

6 Zhu DL, Herembert T, Marche P. Increased proliferation of adventitial fibroblasts from spontaneously hypertensive rat aorta. J Hypertens 1991; 9: 1161-8.

7 Arribas SM, Hillier C, González C, McGrory S, Dominiczak AF, McGrath JC. Cellular aspects of vascular remodeling in hypertension revealed by confocal microscopy. Hypertension 1997; 30: 1455-64.

8 Sun AJ, Gao PJ, Liu JJ, Ji KD, Zhu DL. Osteopontin enhances migratory ability of cultured aortic adventitial fibroblasts from spontaneously hypertensive rats. Sheng Li Xue Bao 2004; 56: 21-4. Chinese.

9 Li L, Zhu DL, Shen WL, Gao PJ. Increased migration of vascular adventitial fibroblasts from spontaneously hypertensive rats. Hypertens Res 2006; 29: 95-103.

10 Yan JX, Wait R, Berkelman T, Harry RA, Westbrook JA, Wheeler $\mathrm{CH}$, et al. A modified silver staining protocol for visualization of proteins compatible with matrix-assisted laser desorption/ionization and electrospray ionization-mass spectrometry. Electrophoresis 2000; 21: 3666-72.

11 Neuhoff V, Arold N, Taube D, Ehrhardt W. Improved staining of proteins in polyacrylamide gels including isoelectric focusing gels with clear background at nanogram sensitivity using Coomassie Brilliant Blue G-250 and R-250. Electrophoresis 1988; 9: 255-62.

12 Jin BF, He K, Wang HX, Wang J, Zhou T, Lan Y, et al. Proteomic analysis of ubiquitin-proteasome effects: insight into the function of eukaryotic initiation factor 5A. Oncogene 2003; 22: 4819-30.

13 Zhou HY, Chen WD, Zhu DL, Wu LY, Zhang J, Han WQ, et al. The PDE1A-PKCalpha signaling pathway is involved in the upregulation of alpha-smooth muscle actin by TGF-beta1 in adventitial fibroblasts. J Vasc Res 2010; 47: 9-15.

14 Walter SV, Hamet P. Enhanced DNA synthesis in heart and kidney of newborn spontaneously hypertensive rats. Hypertension 1986; 8: 520-5.

15 Almawi WY, Lipman ML, Stevens AC, Zanker B, Hadro ET, Strom TB. Abrogation of glucocorticoid-mediated inhibition of T-cell proliferation by the synergistic action of IL-1, IL-6 and IFNY. J Immunol 1991; 146: 3523-9.

16 Skouteris GC, Schroder $\mathrm{CH}$. The hepatocyte growth factor receptor 
kinase-mediated phosphorylation of lipocortin 1 transduces the proliferation signal of the hepatocyte growth factor. J Biol Chem 1996; 271: 27266-73.

17 Almawi WY, Saouda MS, Stevens AC, Lipman ML, Barth CB, Storm TR. Partial mediation of glucocorticoid antiproliferative effects by Lipocortins. J Immunol 1996; 157: 5231-9.

18 Salles JP, Netelenbos JC, Slootweg MC. Growth hormone induces tyrosine phosphorylation of annexin-1 in rat osteosarcoma cells. Endocrinology 1996;137: 4358-62.

19 Schlaepfer DD, Haigler HT. Expression of annexins as a function of cellular growth state. J Cell Biol 1990; 111: 229-38.

20 Alldridge LC, Harris HJ, Plevin R, Hannon R, Bryant CE. Regulation of the mitogen activated protein kinase/ERK pathway by the annexin lipocortin 1. J Biol Chem 1999; 274: 37620-8.

21 Alldridge LC, Bryant CE. Annexin 1 regulates cell proliferation by disruption of cell morphology and inhibition of cyclin D1 expression through sustained activation of the ERK1/2 MAPK signal. Exp Cell Res 2003; 290: 93-107.

22 Shen WL, Gao PJ, Che ZQ, Ji KD, Yin M, Yan C, et al. NAD(P)H oxidasederived reactive oxygen species regulate angiotensin-II induced adventitial fibroblast phenotypic differentiation. Biochem Biophys Res Commun 2006; 339: 337-43.

23 Li L, Zhu DL, Shen WL, Gao PJ. Increased migration of vascular adventitial fibroblasts from spontaneously hypertensive rats. Hypertens Res 2006; 29: 95-103.

24 Gao PJ, Li Y, Sun AJ, Liu JJ, Ji KD, Zhang YZ, et al. Differentiation of vascular myofibroblasts induced by transforming growth factor-beta1 requires the involvement of protein kinase Calpha. J Mol Cell Cardiol 2003; 35: 1105-12.

$25 \mathrm{He}$ H, Chen M, Scheffler NK, Gibson BW, Spremulli LL, Gottlieb RA. Phosphorylation of mitochondrial elongation factor Tu in ischemic myocardium: basis for chloramphenicol-mediated cardioprotection. Circ Res 2001; 89: 461-7.

26 Kraal B, Lippmann C, Kleanthous C. Translational regulation by modifications of the elongation factor Tu. Folia Microbiol (Praha) 1999; 44: 131-41.

27 Heinke MY, Wheeler CH, Chang D, Einstein R, Drake-Holland A, Dunn $\mathrm{MJ}$, et al. Protein changes observed in pacing-induced heart failure using two-dimensional electrophoresis. Electrophoresis 1998; 19: 2021-30.

28 Ying X, Liu Y, Guo Q, Qu F, Guo W, Zhu Y, et al. Endoplasmic reticulum protein 29 (ERp29), a protein related to sperm maturation is involved in sperm-oocyte fusion in mouse. Reprod Biol Endocrinol 2010; 8: 10.

29 Shnyder SD, Hubbard MJ. ERp29 is a ubiquitous resident of the endoplasmic reticulum with a distinct role in secretory protein production. J Histochem Cytochem 2002; 50: 557-66.

30 MacLeod JC, Sayer RJ, Lucocq JM, Hubbard MJ. ERp29, a general endoplasmic reticulum marker, is highly expressed throughout the brain. J Comp Neurol 2004; 477: 29-42.

31 Guo SJ, Wu LY, Wei J, Gao PJ, Zhu DL. Research on proteins associated to differentiation of vascular adventitial myofibroblasts. Acta Chim Sin 2007; 65: 1504-10 